\title{
The effect of an intraoperative, lung- protective ventilation strategy in neurosurgical patients undergoing craniotomy: study protocol for a randomized controlled trial
}

\author{
Liyong Zhang, Wei Xiong, Yuming Peng, Wei Zhang and Ruquan Han *i)
}

\begin{abstract}
Background: Ventilator-induced lung injury is a major cause of postoperative pulmonary complications (PPCs) in patients undergoing neurosurgery after general anesthesia. However, there is no study on the effect of a lungprotective ventilation strategy in patients undergoing neurosurgery.

Methods: This is a single-center, randomized, parallel-group controlled trial which will be carried out at Beijing Tiantan Hospital, Capital Medical University. Three hundred and thirty-four patients undergoing intracranial tumor surgery will be randomly allocated to the control group and the protective-ventilation strategy group. In the control group, tidal volume (VT) will be set at 10-12 $\mathrm{ml} / \mathrm{kg}$ of predicted body weight but PEEP and recruitment maneuvers will not be used. In the protective group, VT will be set at $6-8 \mathrm{ml} / \mathrm{kg}$ of predicted body weight, PEEP at $6-8 \mathrm{cmH}_{2} \mathrm{O}$, and a recruitment maneuver will be used intermittently. The primary outcome is pulmonary complications within 7 days postoperatively. Secondary outcomes include intraoperative brain relaxation, the postoperative complications within 30 days and the cost analysis.
\end{abstract}

Discussion: This study aims to determine if the protective, pulmonary-ventilation strategy decreases the incidence of PPCs in patients undergoing neurosurgical anesthesia. If our results are positive, the study will indicate whether the protective, pulmonary-ventilation strategy is efficiently and safely used in neurosurgical patients undergoing the craniotomy.

Trial registration: ClinicalTrials.gov, ID: NCT02386683. Registered on 18 October 2014.

Keywords: Randomized controlled trial, Lung protection, Postoperative pulmonary complications, Brain relaxation, Craniotomy

\section{Background}

There are at least 234 million patients undergoing major surgeries worldwide each year [1], most of whom need mechanical ventilation when undergoing general anesthesia. Pulmonary complications after mechanical ventilation are the essential reasons for death and disability for patients undergoing general anesthesia $[2,3]$. About $25 \%$ of patients

\footnotetext{
* Correspondence: ruquan.han@gmail.com

Department of Anesthesiology, Beijing Tiantan Hospital, Capital Medical University, No. 6, Tiantan Xili, Dongcheng District, Beijing 100050, People's Republic of China
}

(c) The Author(s). 2018 Open Access This article is distributed under the terms of the Creative Commons Attribution 4.0 International License (http:/creativecommons.org/licenses/by/4.0/, which permits unrestricted use, distribution, and reproduction in any medium, provided you give appropriate credit to the original author(s) and the source, provide a link to the Creative Commons license, and indicate if changes were made. The Creative Commons Public Domain Dedication waiver (http://creativecommons.org/publicdomain/zero/1.0/) applies to the data made available in this article, unless otherwise stated.

suffer from a moderate to high risk of postoperative pulmonary complications (PPCs) by undergoing general anesthesia $[4,5]$. Several risk factors are related with PPCs including preoperative neurological damage associated with dysphagia, longer duration of surgery, and being placed in the lateral or prone positions. Prevention of PPCs improves the quality of medical care and reduces healthcare costs [5].

General anesthesia and surgical positioning leads to a reduction in functional residual capacity and atelectasis $[6,7]$. In the traditional strategy, a tidal volume of 10 to $15 \mathrm{ml} / \mathrm{kg}$ is often used to maintain enough 
gas exchange and intraoperative respiratory dynamics during mechanical ventilation under general anesthesia $[8,9]$. However, recent clinical and laboratory researchers have indicated that high-tidalvolume ventilation leads to alveolar over-inflation, partial pulmonary atelectasis, and ventilator-induced lung injury (VILI) [10, 11]. VILI contributes to organ dysfunction mediated by inflammatory factors. Animal experiments have also confirmed that mechanical ventilation with a high tidal volume leads to acute lung injury in healthy lungs [12, 13], stimulation of cytokine production, release of inflammatory substances and inflammatory cell aggregation [14-16].

The protective, lung-ventilation strategy is defined as the combination of low tidal volume (4 to $8 \mathrm{ml} / \mathrm{kg}$ per body weight), positive end-expiratory pressure (PEEP, > $12 \mathrm{cmH}_{2} \mathrm{O}$, especially $>16 \mathrm{cmH}_{2} \mathrm{O}$ ) and a lung-recruitment method (inspiratory pressure maintained at $30-45 \mathrm{cmH}_{2} \mathrm{O}$ for 30 to $40 \mathrm{~s}$ ). Theoretically, low tidal volume prevents alveolar overexpansion [15], and higher PEEP prevents atelectasis [17]. The protective, lung-ventilation strategy has been confirmed to be the optimal mode of ventilation in patients with acute respiratory distress syndrome (ARDS) [18, 19], and reduces morbidity and mortality. Therefore, the protective-ventilation strategy is strongly recommended in acute respiratory distress syndrome (ARDS) guidelines [20]. However, there is little research on the effect of a protective ventilation strategy on highrisk surgical patients under general anesthesia.

Since 2009, some prospective studies have begun to study the effect of lung-protective ventilation in patients without ARDS [21-23]. Several clinical studies have examined the effect of ventilation settings on the inflammatory response, PPCs and postoperative pulmonary function. Despite the variety of surgical procedures, protective ventilation improved the pulmonary inflammatory response and lung function, and reduced the risk of potential oxygenation deficits in healthy patients undergoing general anesthesia. The results suggested that the use of low tidal volumes in non-ARDS patients efficiently and significantly improved the clinical prognosis. Clinical studies in patients undergoing general anesthesia for abdominal surgery $[24,25]$ as well as meta-analyses and a Cochrane review [26, 27] have shown that PPCs were prevented by a combination of low tidal volume and PEEP. Protective ventilation improved oxygenation and respiratory compliance, and significantly reduced the incidence of VILI.

There are a few studies about the use of the protective, pulmonary-ventilation strategy in neurosurgery. The concern is whether the high-PEEP $(>12$ $\mathrm{cmH}_{2} \mathrm{O}$ ) and lung-recruitment method affect cerebral venous return, decrease brain relaxation and the space for intraoperative operating. However, patients undergoing neurosurgical surgery are often at high risk of PPCs and need particularly close attention. One study showed that high PEEP improved the outcome in a small sample of patients with ARDS after traumatic brain injury, without significantly changing cerebral perfusion and systemic hemodynamic status $[28,29]$. When PEEP increased from 5 to $15 \mathrm{cmH}_{2} \mathrm{O}$, intracranial pressure (ICP) increased from $15 \mathrm{mmHg}$ to $18 \mathrm{mmHg}$ and cerebral perfusion pressure decreased from $78 \mathrm{mmHg}$ to $72 \mathrm{mmHg}$, which were all within acceptable limits. However, there is no randomized controlled trial with a large sample to study the effectiveness and safety of the protective pulmonary ventilation strategies, especially in patients with normal lung tissue undergoing neurosurgical surgery for craniotomy.

The objective of this study was to evaluate the influence of lung-protective ventilation (VT $6-8 \mathrm{ml} / \mathrm{kg}$, PEEP at 6-8 $\mathrm{cmH}_{2} \mathrm{O}$ ) compared with standard ventilation (VT 10-12 $\mathrm{ml} / \mathrm{kg}, \mathrm{PEEP}=0 \mathrm{cmH}_{2} \mathrm{O}$ ) on the occurrence of PPCs among patients undergoing intracranial surgery.

\section{Methods}

Study design

The study is a single-center, randomized, parallelgroup controlled trial which is being conducted at Beijing Tiantan Hospital, Capital Medical University. Approximately 3000 patients receive intracranial primary tumor resection at Tiantan Hospital each year, and 200 to 300 patients could meet the inclusion criteria every year. Study recruitment commenced in August 2015. The schedule of enrollment and assessments is as in the Standard Protocol Items: Recommendations for Interventional Trials (SPIRIT) Figure (Fig. 1 and Additional file 1: SPIRIT checklist).

\section{Randomization and blinding}

Randomization will be conducted via a computergenerated randomized controlled table. Patients who meet the criteria will be randomly allocated to the two groups within $24 \mathrm{~h}$ before surgery. The allocation ratio is $1: 1$. Permuted randomization will be used and stratified by age (older or younger than 60 years). The designated staff will perform the allocation sequence which will be involved in patient recruitment. The designated staff assistants will assign participants to interventions. This research staff will implement the allocation sequence through opaque, sealed and stapled envelopes sequentially numbered corresponding to the computer-generated sequence. Corresponding envelopes will not be opened until the enrolled participants complete the trial. The anesthesiologist who is responsible for the anesthesia implementation will not 


\begin{tabular}{|c|c|c|c|c|c|c|c|c|c|}
\hline \multirow[b]{3}{*}{ TIMEPOINT ${ }^{* *}$} & \multicolumn{9}{|c|}{ STUDY PERIOD } \\
\hline & \multirow{2}{*}{$\begin{array}{c}\text { Enrolment } \\
\text {-1day }\end{array}$} & \multirow{2}{*}{$\begin{array}{c}\begin{array}{c}\text { Allocat } \\
\text { ion }\end{array} \\
\text { Surger } \\
y \text { day }\end{array}$} & \multicolumn{7}{|c|}{ Post-allocation } \\
\hline & & & $\begin{array}{c}\text { Surgery } \\
\text { day }\end{array}$ & 1day & 3day & 5day & $\begin{array}{c}7 \\
\text { day }\end{array}$ & Discharged & $\begin{array}{c}30 \\
\text { day }\end{array}$ \\
\hline \multicolumn{10}{|l|}{ ENROLMENT: } \\
\hline \multirow{4}{*}{$\begin{array}{r}\text { Eligibility screen } \\
\text { Informed consent } \\
\text { [List other } \\
\text { procedures] } \\
\text { Allocation }\end{array}$} & $\mathrm{x}$ & & & & & & & & \\
\hline & $x$ & & & & & & & & \\
\hline & $x$ & & & & & & & & \\
\hline & & $x$ & & & & & & & \\
\hline \multicolumn{10}{|l|}{ INTERVENTIONS: } \\
\hline \multirow{2}{*}{$\begin{array}{r}\text { the traditional } \\
\text { ventilation group } \\
\text { the protective } \\
\text { ventilation group }\end{array}$} & & & $x$ & & & & & & \\
\hline & & & $x$ & & & & & & \\
\hline \multicolumn{10}{|l|}{ ASSESSMENTS: } \\
\hline baseline variables] & $x$ & $x$ & $x$ & & & & & & \\
\hline \multirow{3}{*}{$\begin{array}{r}\text { PPCs } \\
\text { Intraoperative } \\
\text { brain relaxation } \\
\text { The postoperative } \\
\text { complication }\end{array}$} & & & $x$ & $x$ & $x$ & $x$ & $x$ & & $x$ \\
\hline & & & $x$ & & & & & & \\
\hline & & & $\mathrm{x}$ & $x$ & $x$ & $x$ & $x$ & & $x$ \\
\hline \multirow{2}{*}{$\begin{array}{r}\text { Hypoxemia } \\
\text { interleukin 6, } \\
\text { tumor necrosis } \\
\text { factor TNF- } \alpha .\end{array}$} & & & $x$ & $x$ & $x$ & $x$ & $x$ & & $x$ \\
\hline & & & & $x$ & & & & & \\
\hline $\begin{array}{r}\text { Postoperative } \\
\text { antibiotic usage }\end{array}$ & & & & & & & & & $x$ \\
\hline \multirow{2}{*}{$\begin{array}{r}\text { Unanticipated ICU } \\
\text { treatment } \\
I C U \text { stay and } \\
\text { length }\end{array}$} & & & & & & & & & $x$ \\
\hline & & & & & & & & & $x$ \\
\hline $\begin{array}{r}\text { All cause of } \\
\text { mortality }\end{array}$ & & & & & & & & & $x$ \\
\hline Cost analysis & & & & & & & & $x$ & \\
\hline
\end{tabular}

Fig. 1 Schedule of enrollment, intervention and assessments

be blinded to the grouping and will not participate in the follow-up visit. However, the neurosurgeon who evaluates brain relaxation will be blinded to the group allocation. The patients and the outcome assessor are all blinded to the grouping.

\section{Selection and withdrawal of participants Recruitment}

Participants will be recruited from the neurosurgical wards and identified by their presence on surgical lists. The investigator informs the participant or the participant's legal representative of all aspects. The study intervention will be completed immediately after the surgery, but follow-up visits will extend to 1 month after surgery. The medical records will be reviewed following hospital discharge for inhospital complications and medication usage.

\section{Inclusion criteria}

1. Patients scheduled to receive elective. intracranial. primary intra-axial tumor resection at Beijing Tiantan Hospital, Capital Medical University who are older than 40 years

2. Glasgow Coma Scale score of more than 8 points

3. Expected operation time more than $4 \mathrm{~h}$

4. PPCs' risk index grade more than two risk classes (see Table 1) [30]

5. Having signed the informed consent form 
Table 1 Preoperative risk classes of postoperative pulmonary complications (PPCs)

\begin{tabular}{ll}
\hline Preoperative risk factor & Point value \\
\hline Neurosurgery & 8 \\
Age & 17 \\
$\quad \geq 80$ years & 13 \\
70-79 years & 9 \\
60-69 years & 4 \\
50-59 years & \\
Functional status & 10 \\
$\quad$ Totally dependent & 6 \\
Partially dependent & 7 \\
Weight loss $>10 \%$ in past 6 months & 5 \\
History of chronic obstructive pulmonary disease & 4 \\
History of cerebrovascular accident & 4 \\
General anesthesia & 4 \\
Impaired sensorium & 3 \\
Blood urea nitrogen level & 3 \\
$\quad<2.86$ mmol/L (<8 mg/dl) & 3 \\
7.85-10.7 mmol/L (22-308 mg/dl) & 3 \\
$\geq 10.7$ mmol/L ( $\geq 30$ mg/dl) & 3 \\
Transfusion > 4 units & 3 \\
Emergency surgery & 3 \\
Alcohol use for chronic condition & 3 \\
\hline
\end{tabular}

Grade 1: 0-15 points; Grade 2: 16-25 points; Grade 3: 26-40 points; Grade 4: 41-55 points; Grade 5: $>55$ points

\section{Exclusion criteria}

1. Patients with chronic lung disease or pulmonary infection 1 month before the surgery

2. Patients with a history of pulmonary surgery

3. Patients with dysphagia resulting from preoperative cranial nerve damage

4. Patients with large tumors of the skull base who are expected to require a tracheal tube after surgery

5. Body Mass Index more than $35 \mathrm{~kg} / \mathrm{m}^{2}$

6. Acute respiratory failure (pneumonia, acute lung injury, ARDS)

7. Emergency surgery

8. Sepsis or septic shock

9. Progressive neuromuscular disease

10. Pregnant women

11. Heart failure or with severe heart disease

\section{Study intervention}

Ventilation parameter setting during operation

All patients will be randomly allocated to the control group (traditional group) and the protective-ventilation strategy group (protective group) according to the computer-generated random number table. In the control group, VT will be set at $10-12 \mathrm{ml} / \mathrm{kg}$ of predicted body weight, with $\mathrm{PEEP}=0$. The recruitment maneuver will not be used. In the protective group, VT will be set at $6-8 \mathrm{ml} / \mathrm{kg}$ of predicted body weight with PEEP at 6-8 $\mathrm{cmH}_{2} \mathrm{O}$, and the recruitment maneuver will be used intermittently. The predicted body weight of male patients is calculated as $50+0.91 \times$ (centimeters of height - 152.4) and of female patients is calculated as $45.5+$ $0.91 \times$ (centimeters of height -152.4 ) [24]. The lungrecruitment maneuver is maintained as an inspiratory pressure of $30 \mathrm{cmH}_{2} \mathrm{O}$ for $30 \mathrm{~s}$, after tracheal intubation, at the end of surgery and before extubation, respectively. Using lung-recruitment maneuvers in neurosurgery may lead to brain swelling during the operation and increase the risk of cough. When the dura mater is opened, we will do not use the recruitment method. Before using the recruitment method, we need to ensure adequate anesthesia depth or enough muscle relaxation to avoid cough. All patients will receive volume-controlled mechanical ventilation, fraction of inspiration $\mathrm{O}_{2}\left(\mathrm{FiO}_{2}\right)<0.5$, $\mathrm{I}: \mathrm{E}=1: 2$, the respiratory rate will be adjusted according to blood gas analysis results. $\mathrm{PaCO}_{2}$ is maintaining at $30-35 \mathrm{mmHg}$.

\section{Concomitant treatments}

Peripheral venous access will be established before induction. Routine monitoring and data collection include non-invasive blood pressure, electrocardiograph, pulse oxygen saturation, end-tidal carbon dioxide pressure, exhaled anesthetic concentration, and Bispectral Index. All patients will be induced with sufentanil $(0.2$ to $0.3 \mu \mathrm{g} /$ $\mathrm{kg}$ ), propofol $2-2.5 \mu \mathrm{g} / \mathrm{ml}$ and cisatracurium $(1.5 \mathrm{mg} /$ $\mathrm{kg})$. After tracheal intubation, mechanical ventilation will be performed according to the grouping. Inhalation oxygen concentration is $50 \%$. Anesthesia will be maintained with propofol and sevoflurane and remifentanil (0.1 to $0.2 \mu \mathrm{g} / \mathrm{kg} / \mathrm{min}$ ). The target MAC of inhaled anesthesia will be controlled below 0.5 MAC. The Bispectral Index will be maintained between 40 and 60 . Sufentanil will be administered at a specific time point, such as the moment of scalp incision, before the end of the operation. The mean arterial pressure will be maintained between below $20 \%$ and above $10 \%$ of the baseline value. Fluid input and urine output will be monitored closely. Peripheral arterial blood will be sampled at the beginning and end of surgery, 1 day after surgery to measure the routine blood count and blood gas analysis.

\section{Study objective Primary outcome}

The primary outcome of the trial is to investigate whether the protective ventilation reduces the incidence 
of the PPCs within 7 days. The definitions of PPCs will be according to the modified Clinical Pulmonary Infection Score (mCPIS) (see Table 2) [31]. We define no pulmonary infection when the grade is zero. We define this

Table 2 Modified Clinical Pulmonary Infection Score (mCPIS)

\begin{tabular}{ll}
\hline Classification & Grading basis \\
\hline Grade 1 & Dry cough \\
& Atelectasis: extrapulmonary exclude other causes of body \\
& temperature $37.5^{\circ} \mathrm{C}$, or abnormal pulmonary symptoms \\
& or signs; radiological examination was normal \\
& Difficulty in breathing (other causes excluded from the lung) \\
& Cough and sputum don'ts due to other causes (heart \\
Grade 2 & failure, etc.) \\
& Bronchospasm: wheeze, or the original wheeze need \\
& treatment \\
& Hypoxemia \\
& atelectasis: radiological evidence; body temperature> \\
& 37.5Cor abnormal lung symptoms or signs \\
& Transient hypercapnia requiring treatment such as \\
& naloxone; assisted or mechanical ventilation \\
& Pleural effusion, pleurisy \\
& Pneumonia, suspected: radiological evidence; no positive \\
& bacterial culture results \\
& Pneumonia, diagnosis: radiological evidence; bacterial \\
& culture evidence \\
& Pneumothorax \\
& Postoperative reintubation or retention of intubation \\
& respiratory support (including noninvasive and invasive) \\
& $\leq 48$ hrs. \\
& Respiratory failure: postoperative non-invasive respiratory \\
& support $\geq 48$ hours; or re-endotracheal intubation \\
& ventilator support $\geq 48$ hrs
\end{tabular}

* Postoperative hypoxemia diagnostic criteria: suction air $\mathrm{PaO}_{2}<60 \mathrm{mmHg}$, or $\mathrm{SpO}_{2}<90 \%$; or $\mathrm{PaO}_{2} / \mathrm{FiO}_{2} \leq 300$

* Pneumonia diagnostic criteria: new chest radiograph or progression of infiltrative lung lesions, combined with the following two or more can be diagnosed: (1) body temperature $\geq 38.5^{\circ} \mathrm{C}$ or $<36{ }^{\circ} \mathrm{C}$; (2) WBC $>12 \times 109$ or $<$ $4 \times 109$; (3) purulent sputum and/or new or aggravated cough and expectoration

* Atelectasis diagnostic criteria: (1) atelectasis by $\mathrm{x}$-ray signs: atelectasis of the lung tissue through decrease in brightness; increased homogeneity of a radiological density; bronchiectasis can be associated with non-homogeneous density (cystic translucent area) in convalescence. Different degrees of volume reduction, subsegmental and distal to the pulmonary atelectasis may have other collateral ventilation routes and volume reduction is not obvious. Leaf segmental atelectasis is generally blunt, triangular, wide and face towards the diaphragmatic pleural surface, the tip pointing to the hilum, in a fan, triangle, band, circle, etc. (2) Computed tomography (CT) imaging above costophrenic angle $1 \mathrm{~cm}$

* Systemic inflammatory response syndrome (SIRS) diagnostic criteria: two or more of the following clinical manifestations: (1) body temperature $>38^{\circ} \mathrm{C}$ or $<36^{\circ} \mathrm{C}$; (2) heart rate $>90$ beats $/ \mathrm{min}$; WBC $>12 \times 109$ or $<4 \times 109$ or myeloblast count $>10 \%$

Diagnosis of sepsis: (1) systemic infection: positive microbial blood culture, or tissue infection or evidence of abscess formation (such as: pneumonia, peritonitis, urinary tract infection, central venous catheter infection, soft tissue infections); (2) at least two SIRS criteria

* Criteria of diagnosis of severe sepsis: sepsis, combined with at least one organ failure, hypotension or hypoperfusion

* Diagnostic criteria for Chinese toxic shock syndrome: infection-induced hypotension, although the volume of treatment but there are still important organs and tissue hypoperfusion as a pulmonary complication if the grade is greater than zero ( 1 to 4 , indicate to severe). The mCPIS includes symptoms and signs (such as a dry cough and sputum), chest $\mathrm{x}$-ray, blood and sputum laboratory tests, blood gas analysis and body temperature after surgery, etc.

\section{Secondary outcome}

The secondary outcomes are as follows:

1. Intraoperative brain relaxation. Brain relaxation will be scored by the neurosurgeon after opening the cranium and before opening the dura. They will use a 4-point scale: 1 , completely relaxed; 2 , satisfactorily relaxed; 3 , firm brain; 4 , bulging brain

2. The airway peak pressure at different time points during operation, such as skin incision, drilling, opening the dura, tumor resection, hemostasis, suturing the dura, the end of surgery

3. The postoperative complications within 30 days including:

(a) Surgical complications, including intracranial infection, incision infection, cerebral edema or bleeding requiring re-operative surgery

(b) PPCs

(c) Systematic complications (systemic inflammatory response syndrome; septic shock, etc.)

(d)Death

4. Postoperative gas exchange disorder (hypoxemia) within 30 days: when the patient breathes air, partial pressure of oxygen $\left(\mathrm{PaO}_{2}\right)$ less than $60 \mathrm{mmHg}$, or Pulse Oxygen Saturation $\left(\mathrm{SpO}_{2}\right)$ less than $90 \%$; or $\mathrm{PaO}_{2} / \mathrm{FiO}_{2}$ less than 300 .

5. Peripheral blood inflammatory response indicators on the first postoperative day: interleukin-6, tumor necrosis factor TNF- $\alpha$

6. Postoperative antibiotic usage within 30 days

7. Unanticipated intensive care unit (ICU) treatment within 30 days

8. ICU stay and length of hospital stay within 30 days

9. All-cause of mortality at 30 days

10.Cost analysis: data on the cost of treatment will include standardized costs for physiotherapy, neurosurgery, anesthesia and postoperative care. Data will be presented regarding total non-operative costs, costs per day.

\section{Reporting of adverse events}

All adverse events will be recorded and closely monitored until resolution or stabilization or until it has been shown that potential conflicts of interest regarding the study treatment are not the cause of the event. In the event of any serious adverse event, it will be immediately reported to the Endpoint Adjudication Committee, which will determine the severity and causality of the 
adverse events. The chief investigator will be responsible for all adverse event reporting.

\section{Withdrawal from the trial}

We will consider patient withdrawal from the trial if the following conditions occur: (1) severe brain swelling during the operation; (2) the patient has a cough during surgery; (3) the patient has persistent hypotension and circulatory instability.

\section{Data collect and management}

We can obtain all the patient information through the electronic medical record system. We also obtained the consent of the neurosurgeon and the radiologist who will help us make the neurological diagnosis. All personal information will be collected through the hospitalized medical records by a member of the research team and be kept strictly confidential for research purposes only. The research team members will be responsible for maintaining personal data. Only the primary investigator and the designated researcher can obtain interim results and final test data.

\section{Data Monitoring Committee (DMC)}

The project will be monitored by a Data Monitoring Committee (DMC) composed of specialists in anesthesiology, ethics, statistics and methodology. The DMC will audit through regular interviews or telephone calls.

\section{Sample size and justification}

We calculated the sample size through the website http://www.sample-size.net/sample-size-proportions/.

The incidence of pulmonary complications was $36 \%$ after about $2 \mathrm{~h}$ of abdominal surgery within 7 days [24], in which PPCs were assessed through the mCPIS. When the duration of intracranial surgery was more than $300 \mathrm{~min}$, the probability of PPCs was $28.4 \%$ [32], in which PPCs were defined as pneumonia, tracheobronchitis, atelectasis and bronchoconstriction. However, if the PPCs were defined by using the mCPIS scale from grades 1 to 4, the incidence of PPCs would significantly increase to more than $28.4 \%$. In our study, the duration of surgery is expected to be more than $5 \mathrm{~h}$ and the PPCs are evaluated by the mCPIS, So, we estimate that the incidence of PPCs would be greater than $36 \%$, and define $40 \%$ as the incidence of the PPCs.

Protective lung ventilation leads to the incidence of pulmonary complications decreasing from $36 \%$ to $17.5 \%$ in patients undergoing abdominal surgery [24], which was consistent with the Cochrane review [27]. Therefore, we also define the effect size of the protective lung ventilation as $18.5 \%$.

So, we set $\mathrm{P} 0=40 \%, \mathrm{P} 1=40 \%-18.5 \%=21.5 \%, \alpha=0.05$ and $\beta=0.1$. The allocation ratio is $1: 1$. The sample size is 278 . Taking account the dropout rate of $20 \%$, the total sample size is 334 cases [33, 34].

\section{Statistics}

The SPSS 19.0 software package for Windows (SPSS, Inc., Chicago, IL, USA) will be used for all statistical analyses. The primary outcome will be expressed as the number of patients (percentage) or median (interquartile range $(\mathrm{IQR})$ ), and analyzed by using the chi-square $\left(\mathrm{x}^{2}\right)$ and Fisher's exact tests. The difference in severity of pulmonary complications between the two groups will be made based on the patient grading score of the two groups. We will use the Mann-Whitney $U$ test for analysis. Brain relaxation will use the Mann-Whitney $U$ test for analysis. The airway peak pressure, cost analysis, ICU stay and length of hospital stay, postoperative antibiotic usage, and peripheral blood inflammatory response indicators will use a one-way analysis of variance. The incidence of postoperative complications within 30 days, hypoxemia, unanticipated ICU treatment and all-cause mortality at 30 days will be expressed as the number of patients (percentage) or median (interquartile range (IQR)), and analyzed by using the chi-square $\left(x^{2}\right)$ or Fisher's exact tests.

When the follow-up visits of 150 participants are completed (estimated to occur after 18 months of recruitment), the interim analysis will be conducted to evaluate the efficacy of the primary outcome. The $p$ value for the analysis will be set at $p<0.001$ using the alpha-sparing technique (O’Brien-Fleming) for benefit or harm.

\section{Discussion}

This study is a randomized controlled trial on the effect of protective lung ventilation on PPCs in patients undergoing neurosurgery. There has been little attention paid so far to patients undergoing craniotomy. However, the incidence of neurological PPCs is relatively high. Qaseem et al. [35] reported that the risk of PPCs increased when surgical duration is more than $4 \mathrm{~h}$. The incidence of PPCs was 28.4\% (20.2-37.9\%) in patients with neurosurgery lasting for longer than $300 \mathrm{~min}$ [32].

PEEP is proposed to reduce the incidence of postoperative respiratory complications. PEEP may prevent atelectasis, and reduce the risk of VILI. Higher PEEP use in neurosurgery is relatively limited because higher PEEP may lead to increase airway pressure, decreased cerebral venous return and intraoperative operating space. Recent research has provided compelling evidence that lung-protective mechanical ventilation using lower tidal volumes, moderate PEEP $\left(6-8 \mathrm{cmH}_{2} \mathrm{O}\right)$ and lung-recruitment maneuvers were associated with improved functional or physiological and clinical postoperative outcome in patients undergoing abdominal surgery [36]. We also observed peak airway pressure less than 20 
$\mathrm{cmH}_{2} \mathrm{O}$ in the pilot study and adequate operating space was not affected. Therefore, we will use moderate PEEP $\left(6-8 \mathrm{cmH}_{2} \mathrm{O}\right)$ to avoid the effects of the higher PEEP on intracranial pressure (ICP) in this study.

Whether PEEP can be safely used in craniotomy is a critical issue. So, the brain relaxation evaluations will be performed before dural incision. If intracranial pressure increases sufficient to affect the operation by using PEEP, we will abandon the case and change the parameter of ventilation. This case will be reported to the primary investigator.

The study is a prospective, randomized controlled, double-blind trial. This study aims to determine whether the protective pulmonary ventilation can be efficiently and safely used in neurosurgical patients undergoing the craniotomy. If we can prove that protective lung ventilation can reduce the incidence of PPCs in patients undergoing craniotomy, it will improve the prognosis of neurosurgical patients and decrease medical costs.

\section{Trial status}

The study was also registered on the registry website http://clinicaltrails.gov/ with the registration number NCT02386683 on 18 October 2014. The study began on 1 October 2015, and the planned completion date will be March 2018. Trial status was currently recruiting.

\section{Additional file}

Additional file 1: SPIRIT Checklist. (DOCX $41 \mathrm{~kb}$ )

\section{Abbreviations}

PPCs: Postoperative pulmonary complications; VT: Tidal volume ICP: Intracranial pressure; VILI: Ventilator-induced lung injury; PEEP: Positive end-expiratory pressure; ARDS: Acute respiratory distress syndrome; $\mathrm{PaO}_{2}$ : Partial pressure of oxygen; $\mathrm{SpO}_{2}$ : Pulse oxygen saturation; $\mathrm{FiO}_{2}$ : Fraction of inspiration $\mathrm{O}_{2}$

\section{Acknowledgements}

Not applicable.

\section{Funding}

The trial was funded by the Beijing Municipal Administration of Hospitals Clinical Medicine Development of Special Funding Support (code number: ZYLX201708). The funder will not participate in the study design; collection, management, analysis and interpretation of data; writing of the report; and the decision to submit the report for publication.

\section{Availability of data and materials}

Not applicable.

\section{Patient consent}

Patients who participate in the trial will have their informed consent obtained by a member of the research team. All patients will be given a clear explanation and enough time to consider participation in the trial. The approval will be given 2 days before surgery.

\section{Authors' contributions}

LZ was involved in conception and design, data collection and analysis, manuscript writing and final approval of the manuscript. WX was involved in conception and design, data collection, manuscript revision and final approval of the manuscript. YP was involved in conception and design, data collection and manuscript revision. WZ was involved in conception and design, data collection and manuscript revision. $\mathrm{RH}$ was involved in conception and design, data analysis, manuscript revision and final approval of the manuscript, and he is the responsible author. All authors have read and approved the final manuscript.

\section{Ethics approval and consent to participate}

The trial will be conducted by the ethical principles outlined in the Declaration of Helsinki, 1996 [14]; National Ethics Review for Biomedical Research Involving Humans (Trial), 2007 [15]; and International Ethical Guidelines for Biomedical Research Involving Human Subjects, 2002 [16]. Approval was obtained from the Ethics Committee of Beijing Tiantan Hospital on 18 October 2014 (reference number KY-2014-031-02).

\section{Consent for publication}

Not applicable

\section{Competing interests}

The authors declare that they have no competing interests.

\section{Publisher's Note}

Springer Nature remains neutral with regard to jurisdictional claims in published maps and institutional affiliations.

Received: 17 April 2017 Accepted: 3 January 2018

Published online: 02 February 2018

\section{References}

1. Weiser TG, Regenbogen SE, Thompson KD, Haynes AB, Berry WR, Gawande AA. An estimation of the global volume of surgery: a modeling strategy based on available data. Lancet. 2008:372:139-44.

2. Fernandez-Bustamante A, Frendl G, Sprung J, Subramaniam B, Martinez Ruiz R, Lee JW, Henderson WG, Moss A, Mehdiratta N, Colwell MM, Bartels K, Kolodzie K, Giquel J, Vidal Melo MF. Postoperative pulmonary complications, early mortality, and hospital stay following noncardiothoracic surgery: a multicenter study by the perioperative research network investigators. JAMA Surg. 2017;152(2):157-66.

3. Finks JF, Osborne NH, Birkmeyer JD. Trends in hospital volume and operative mortality for high-risk surgery. N Engl J Med. 2011;364:2128-37.

4. Arozullah AM, Daley J, Henderson WG, Khuri SF. Multifactorial risk index for predicting postoperative respiratory failure in men after major noncardiac surgery: the National Veterans Administration Surgical Quality Improvement Program. Ann Surg. 2000;232:242-53.

5. Shander A, Fleisher LA, Barie PS, Bigatello LM, Sladen RN, Watson CB. Clinical and economic burden of postoperative pulmonary complications: patient safety summit on definition, risk-reducing interventions, and preventive strategies. Crit Care Med. 2011;39:2163-72

6. Hedenstierna $G$, Edmark L. The effects of anesthesia and muscle paralysis on the respiratory system. Intensive Care Med. 2005:31:1327-35.

7. Bendixen $\mathrm{HH}$, Hedley-Whyte J, Laver MB. Impaired oxygenation in surgical patients during general anesthesia with controlled ventilation. A concept of atelectasis. N Engl J Med. 1963;269:991-6.

8. Wrigge $H$, Pelosi P. Tidal volume in patients with normal lungs during general anesthesia: lower the better? Anesthesiology. 2011;114:1011-3.

9. Blum JM, Fetterman DM, Park PK, Morris M, Rosenberg AL. A description of intraoperative ventilator management and ventilation strategies in hypoxic patients. Anesth Analg. 2010;110:1616-22.

10. Lellouche F, Dionne S, Simard S, Bussières J, Dagenais F. High tidal volumes in mechanically ventilated patients increase organ dysfunction after cardiac surgery. Anesthesiology. 2012;116:1072-82.

11. Tremblay LN, Slutsky AS. Pathogenesis of ventilator-induced lung injury: trials and tribulations. Am J Physiol Lung Cell Mol Physiol. 2005;288:L596-8.

12. De Prost N, Costa EL, Wellman T, Musch G, Tucci MR, Winkler T, Harris R, Venegas JG, Kavanagh BP, Vidal Melo MF. Effects of ventilation strategy on distribution of lung inflammatory cell activity. Crit Care. 2013;17:R175. 
13. Kroon AA, Delriccio V, Tseu I, Kavanagh BP, Post M. Mechanical ventilationinduced apoptosis in newborn rat lung is mediated via FasL/Fas pathway. Am J Physiol Lung Cell Mol Physiol. 2013;305:L795-804.

14. Gurkan OU, O'Donnell C, Brower R, Ruckdeschel E, Becker PM. Differential effects of mechanical ventilatory strategy on lung injury and systemic organ inflammation in mice. Am J Physiol Lung Cell Mol Physiol. 2003;285:L710-8.

15. Tojo K, Nagamine Y, Yazawa T, Mihara T, Baba Y, Ota S, Goto T, Kurahashi K. Atelectasis causes alveolar hypoxia-induced inflammation during uneven mechanical ventilation in rats. Intensive Care Med Exp. 2015;3(1):56.

16. Lu Q. How to assess positive end-expiratory pressure-induced alveolar recruitment? Minerva Anestesiol. 2013;79(1):83-91.

17. Chikhani M, Das A, Haque M, Wang W, Bates DG, Hardman JG. High PEEP in acute respiratory distress syndrome: quantitative evaluation between improved arterial oxygenation and decreased oxygen delivery. $\mathrm{Br} J$ Anaesth. 2016;117(5):650-8

18. Cho YJ, Moon JY, Shin ES, Kim JH, Jung H, Park SY, Kim HC, Sim YS, Rhee CK, Lim J, Lee SJ, Lee WY, Lee HJ, Kwak SH, Kang EK, Chung KS, Choi WI. Clinical practice guideline of acute respiratory distress syndrome. Tuberc Respir Dis (Seoul). 2016;79(4):214-33.

19. Bime C, Fiero M, Lu Z, Oren E, Berry CE, Parthasarathy S, Garcia JG. High positive end-expiratory pressure is associated with improved survival in obese patients with acute respiratory distress syndrome. Am J Med. 2017; 130(2):207-13.

20. Dellinger RP, Levy MM, Carlet JM, Bion J, Parker MM, Jaeschke R, Reinhart K, Angus DC, Brun-Buisson C, Beale R, Calandra T, Dhainaut JF, Gerlach H, Harvey M, Marini JJ, Marshall J, Ranieri M, Ramsay G, Sevransky J, Thompson BT, Townsend S, Vender JS, Zimmerman JL, Vincent JL. Surviving Sepsis Campaign: international guidelines for management of severe sepsis and septic shock: 2008. Crit Care Med. 2008;36:296-327.

21. Sundar S, Novack V, Jervis K, Bender SP, Lerner A, Panzica P, Mahmood F, Malhotra A, Talmor D. Influence of low tidal volume ventilation on time to extubation in cardiac surgical patients. Anesthesiology. 2011;114:1102-10.

22. Treschan TA, Kaisers W, Schaefer MS, Bastin B, Schmalz U, Wania V, Eisenberger CF, Saleh A, Weiss M, Schmitz A, Kienbaum P, Sessler DI, Pannen B, Beiderlinden M. Ventilation with low tidal volumes during upper abdominal surgery does not improve postoperative lung function. $\mathrm{Br}$ J Anaesth. 2012;109:263-71.

23. Severgnini P, Selmo G, Lanza C, Chiesa A, Frigerio A, Bacuzzi A, Dionigi G, Novario R, Gregoretti C, de Abreu MG, Schultz MJ, Jaber S, Futier E, Chiaranda M, Pelosi P. Protective mechanical ventilation during general anesthesia for open abdominal surgery improves postoperative pulmonary function. Anesthesiology. 2013;118:1307-21.

24. Futier $E$, Constantin JM, Paugam-Burtz C, Pascal J, Eurin M, Neuschwander A, Marret E, Beaussier M, Gutton C, Lefrant JY, Allaouchiche B, Verzilli D, Leone M, De Jong A, Bazin JE, Pereira B, Jaber S. A trial of intraoperative low-tidalvolume ventilation in abdominal surgery. N Engl J Med. 2013;369:428-37.

25. Serpa Neto A, Cardoso SO, Manetta JA, Pereira VG, Espósito DC, Pasqualucci Mde O, Damasceno MC, Schultz MJ. Association between use of lung protective ventilation with lower tidal volumes and clinical outcomes among patients without acute respiratory distress syndrome: a metaanalysis. JAMA. 2012;308(16):1651-9.

26. Yang D, Grant MC, Stone A, Wu CL, Wick EC. A meta-analysis of intraoperative ventilation strategies to prevent pulmonary complications: is low tidal volume alone sufficient to protect healthy lungs? Ann Surg. 2016; 263(5):881-7.

27. Guay J, Ochroch EA. Intraoperative use of low volume ventilation to decrease postoperative mortality, mechanical ventilation, lengths of stay and lung injury in patients without acute lung injury. Cochrane Database Syst Rev. 2015;Dec 7(12):CD011151.

28. Boone MD, Jinadasa SP, Mueller A, Shaefi S, Kasper EM, Hanafy KA, O'Gara $\mathrm{BP}$, Talmor DS. The effect of positive end-expiratory pressure on intracranial pressure and cerebral hemodynamics. Neurocrit Care. 2017;26(2):174-81.

29. Huynh T, Messer M, Sing RF, Miles W, Jacobs DG, Thomason MH. Positive end-expiratory pressure alters intracranial and cerebral perfusion pressure in severe traumatic brain injury. J Trauma. 2002;53:488-92.

30. Arozullah AM, Khuri SF, Henderson WG, Daley J. Development and validation of a multifactorial risk index for predicting postoperative pneumonia after major noncardiac surgery. Ann Intern Med. 2001:135:847-57.

31. Kroenke K, Lawrence VA, Theroux JF, Tuley MR. Operative risk in patients with severe obstructive pulmonary disease. Arch Intern Med. 1992;152:967-71.
32. Sogame LC, Vidotto MC, Jardim JR, Faresin SM. Incidence and risk factors for postoperative pulmonary complications in elective intracranial surgery. Neurosurg. 2008;109(2):222-7.

33. Hulley SB, Cummings SR, Browner WS. Designing clinical research: an epidemiologic approach. 4th ed. Philadelphia: Lippincott Williams \& Wilkins; 2013. p. 75.

34. Fleiss JL, Tytun A, Ury HK. A simple approximation for calculating sample sizes for comparing independent proportions. Biometrics. 1980;36:343-6.

35. Qaseem A, Snow V, Fitterman N, Hornbake ER, Lawrence VA, Smetana GW Weiss K, Owens DK, Aronson M, Barry P, Casey Jr DE, Cross Jr JT, Fitterman $\mathrm{N}$, Sherif KD, Weiss KB. Risk assessment for and strategies to reduce perioperative pulmonary complications for patients undergoing noncardiothoracic surgery: a guideline from the American College of Physicians. Ann Intern Med. 2006;144(8):575-80.

36. De Jong MA1, Ladha KS, Melo MF, Staehr-Rye AK, Bittner EA, Kurth T, Eikermann M. Differential effects of intraoperative positive end-expiratory pressure (PEEP) on respiratory outcome in major abdominal surgery versus craniotomy. Ann Surg. 2016;264(2):362-9.

\section{Submit your next manuscript to BioMed Central and we will help you at every step:}

- We accept pre-submission inquiries

- Our selector tool helps you to find the most relevant journal

- We provide round the clock customer support

- Convenient online submission

- Thorough peer review

- Inclusion in PubMed and all major indexing services

- Maximum visibility for your research

Submit your manuscript at www.biomedcentral.com/submit
) Biomed Central 